\title{
Back-stresses and geometrical hardening as competing mechanisms enhancing ductility in HCP metals
}

DOI:

10.1016/j.msea.2018.05.046

\section{Document Version}

Accepted author manuscript

Link to publication record in Manchester Research Explorer

\section{Citation for published version (APA):}

Esque-De Los Ojos, D., Nguyen, C-T., Orozco-Caballero, A., Timar, G., \& Quinta da Fonseca, J. (2018). Backstresses and geometrical hardening as competing mechanisms enhancing ductility in HCP metals. Materials Science and Engineering A: Structural Materials: Properties, Microstructures and Processing . https://doi.org/10.1016/j.msea.2018.05.046

Published in:

Materials Science and Engineering A: Structural Materials: Properties, Microstructures and Processing

\section{Citing this paper}

Please note that where the full-text provided on Manchester Research Explorer is the Author Accepted Manuscript or Proof version this may differ from the final Published version. If citing, it is advised that you check and use the publisher's definitive version.

\section{General rights}

Copyright and moral rights for the publications made accessible in the Research Explorer are retained by the authors and/or other copyright owners and it is a condition of accessing publications that users recognise and abide by the legal requirements associated with these rights.

\section{Takedown policy}

If you believe that this document breaches copyright please refer to the University of Manchester's Takedown Procedures [http://man.ac.uk/04Y6Bo] or contact uml.scholarlycommunications@manchester.ac.uk providing relevant details, so we can investigate your claim.

\section{OPEN ACCESS}




\section{Author's Accepted Manuscript}

Back-stresses and geometrical hardening as competing mechanisms enhancing ductility in $\mathrm{HCP}$ metals

D. Esqué-de los Ojos, C.-T. Nguyen, A. OrozcoCaballero, G. Timár, J. Quinta da Fonseca

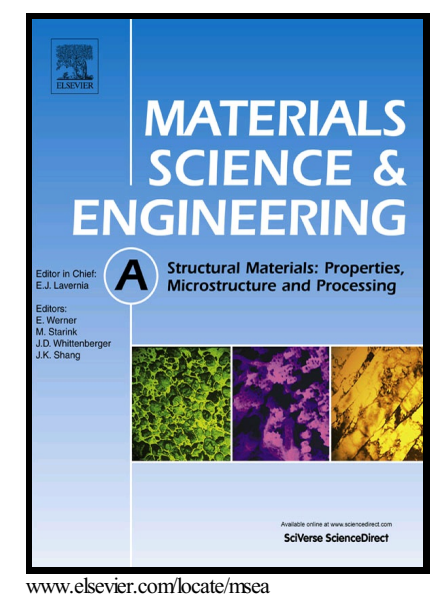

PII: $\quad$ S0921-5093(18)30695-6

DOI: $\quad$ https://doi.org/10.1016/j.msea.2018.05.046

Reference: MSA36484

To appear in: $\quad$ Materials Science \& Engineering $A$

Received date: 12 February 2018

Revised date: 7 May 2018

Accepted date: 14 May 2018

Cite this article as: D. Esqué-de los Ojos, C.-T. Nguyen, A. Orozco-Caballero, G. Timár and J. Quinta da Fonseca, Back-stresses and geometrical hardening as competing mechanisms enhancing ductility in HCP metals, Materials Science \& Engineering A, https://doi.org/10.1016/j.msea.2018.05.046

This is a PDF file of an unedited manuscript that has been accepted for publication. As a service to our customers we are providing this early version of the manuscript. The manuscript will undergo copyediting, typesetting, and review of the resulting galley proof before it is published in its final citable form. Please note that during the production process errors may be discovered which could affect the content, and all legal disclaimers that apply to the journal pertain. 


\title{
ACCEPTED MANUSCRIPT
}

\section{Back-stresses and geometrical hardening as competing mechanisms enhancing ductility in HCP metals}

\author{
D. Esqué-de los Ojos ${ }^{1,2 *}$, C.-T. Nguyen ${ }^{1}$, A. Orozco-Caballero ${ }^{1}$, G. Timár ${ }^{1,3}$, \\ J. Quinta da Fonseca ${ }^{1}$ \\ ${ }^{1}$ School of Materials, University of Manchester, \\ MSS Tower, Manchester M13 9PL, UK \\ ${ }^{2}$ Tech Institute for Advanced Materials, School of Materials Science and Engineering, \\ Nanjing Tech University, Nanjing 210009, China \\ ${ }^{3}$ Department of Physics \& I3N, University of Aveiro, \\ Campus Universitário de Santiago, 3810-193 Aveiro, Portugal
}

\begin{abstract}
By recourse of computational mechanics, back-stresses are unveiled as a major source for the increase in work hardening during forming of hexagonal close-packaged (hcp) metals. Polycrystalline visco-plastic self-consistent (VPSC) and crystal plasticity finite element modelling (CPFEM) simulations of tensile uniaxial experiments were used along with experimental texture information. Simulations took into account the analogous variation in the critical resolved shear stress (CRSS) values of each slip family that could result from an increase in the test temperature. As the CRSS ratio between secondary and primary slip families increased, two different contributions to the variation of the work hardening rate were observed depending on the simulation framework: (i) a decrease in the work hardening rate in VPSC simulations attributed to texture evolution or geometrical hardening and (ii) an increase in the work hardening rate in CPFEM simulations due to back-stresses. While geometrical hardening is present in both simulation frameworks, only CPFEM is able to capture the influence of back-stresses on the increase of the work hardening rate with temperature. The results provided here contribute to a better understanding of the deformation mechanisms present in warm forming of hcp metals, showing also that CPFEM is a better simulation framework to study warm forming of hcp metals.
\end{abstract}

\section{Submitted to Materials Science and Engineering A}

May 15, 2018

\footnotetext{
*Corresponding author. e-mail: danielesque@gmail.com
} 


\section{Introduction}

The predictions of forming limits and spring-back in forming operations rely on the faithful capture of the material work hardening behaviour. Work hardening is caused by dislocation accumulation, texture evolution (geometric hardening) and back-stresses [1]. While dislocation hardening dominates during room temperature deformation, during warm forming, i.e. at higher temperatures but below the recrystallization temperature, the contribution by dislocation accumulation is limited by recovery and other sources of work hardening become more important.

One of the difficulties is that both geometric and back-stress hardening are strongly anisotropic and highly dependent on the loading mode, in a way that is not easy to capture empirically. Instead, researchers have suggested the use of crystal plasticity models to capture the hardening behaviour associated with texture evolution. Such attempts have traditionally employed the visco-plastic self-consistent (VPSC) model formulations and have shown some success $[2,3]$.

The VPSC model provides access to the path dependent texture (geometric) hardening but (usually) ignores the contribution of back-stress. Back-stresses arise from deformation heterogeneity and arise naturally from the elegant elastic energy-based treatment by Tanaka and Mori [4] of the work hardening in metals containing undeformable particles. In single phase metal plasticity, back-stresses are generated due to differences in strain rate between grains well aligned for slip ("soft grains") and grains poorly aligned for slip ("hard grains"). In cubic metals the difference between hard and soft grains will usually be small and disappear with increasing plastic deformation through the action of work hardening. However, in hexagonal metals the plastic anisotropy is very high and there is good evidence that the strain rates in hard grains are much lower than that in soft grains and that this anisotropy does not vanish with increasing plastic strain e.g. [5]. Therefore, the contribution of back-stress to hardening could be significant at large strains, affecting significantly both shape and forming limit predictions.

Because the VPSC model does not account for the elastic interaction between grains, it cannot predict the effect of back-stresses on the work hardening. On the other hand, in full field methods like crystal plasticity finite element modelling (CPFEM), the elastic interactions between hard and soft grains are implicitly accounted for. Hence it should be able to capture these back-stress effects. The CPFEM approach is much more computationally intensive than VPSC modelling and therefore it is worthwhile to determine whether the back-stress contribution 


\section{ACCEPTED MANUSCRIPT}

to work hardening is indeed significant, or only a second order effect which can be neglected.

It has recently been proposed that back-stresses are responsible for the abnormal variation of work hardening behaviour with temperature observed in commercially pure titanium. Ultimately explaining why the uniform elongation in uniaxial tension increases with temperature [6]. The corresponding experimental (quasi-static) stress-strain curves at different temperatures are shown in Figure 1, alongside the work hardening curves. As expected, increasing the temperature leads to a decrease in the yield stress $\left(\sigma_{0.2}\right)$ and in maximum flow stress $\left(\sigma_{\max }\right)$. However, it is clear that the work hardening at RT is higher but drops off quickly leading to necking and failure. On the other hand, the work hardening at higher temperature (HT) is lower at the start but remains relatively high for much longer, delaying necking and increasing the elongation to failure.
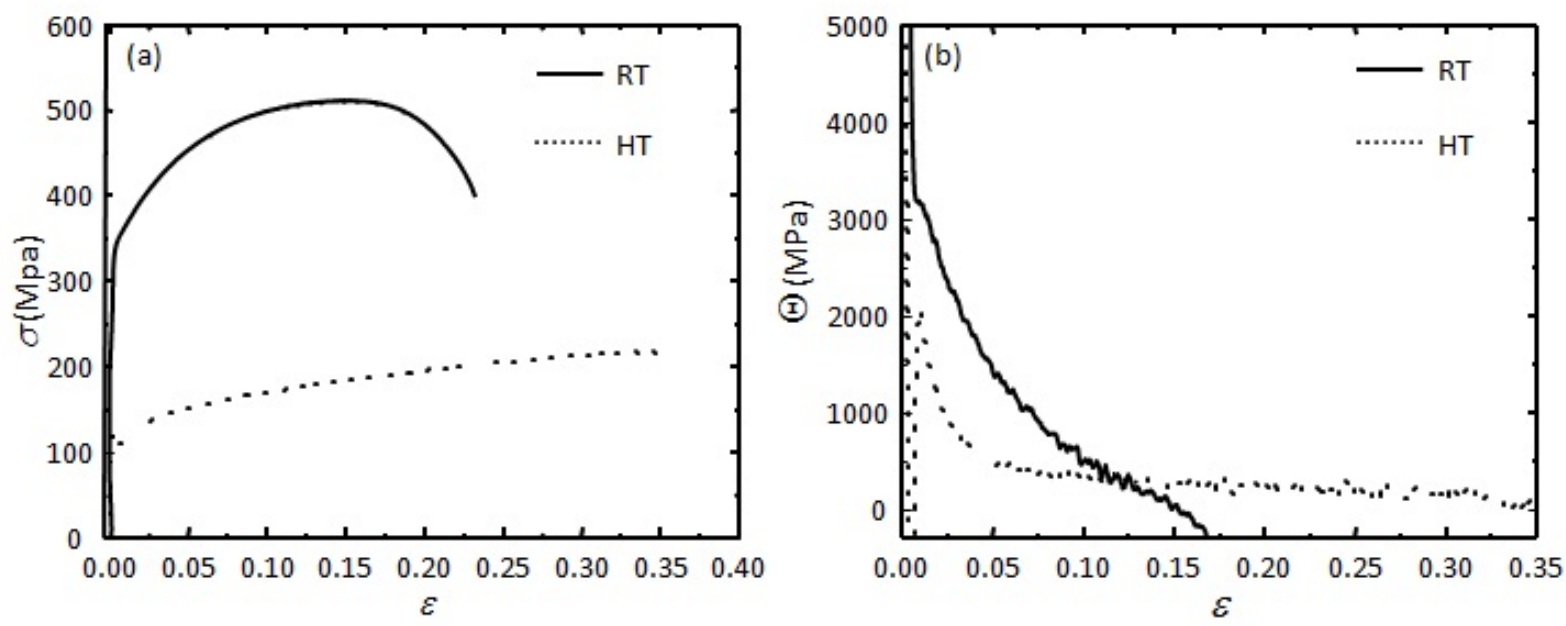

Figure 1: Experimental (a) uniaxial stress $(\sigma)$ - strain $(\epsilon)$ and $($ b) work hardening rate $(\Theta)$ strain $(\epsilon)$ curves for CP-Ti. Solid line at room temperature (RT) and dotted line at a high temperature (HT) of $300^{\circ} \mathrm{C}$.

This change in hardening behaviour was attributed to increasing single crystal anisotropy with increasing temperature, and to the concomitant increase in the back-stress contribution to work hardening. Although CPFEM was used to support this interpretation, it was not possible to separate the relative contributions of back-stresses and geometric hardening to the work hardening behaviour, ruling out geometric hardening as an explanation for the enhanced hardening at higher temperatures.

In this paper we explore the relative contributions of texture and back-stresses to work hardening in hexagonal metals by comparing the hardening predictions of a VPSC model and a CPFE 


\section{ACCEPTED MANUSCRIPT}

model. Whereas both models should predict the effects of texture hardening, only the CPFE model can predict the back-stress contribution. We study three polycrystalline systems modelled on zirconium, titanium and magnesium alloys. Each system has different characteristic variations in relative slip resistance, and slightly different starting textures, which are nevertheless very similar in character. The aim was to understand, from a computational point of view, the extent to which back-stresses do affect the work hardening in these systems, to explore the implications of ignoring their contribution and to determine the best simulation framework.

Both models were used to simulate deformation in uniaxial tension, from which the work hardening rates were calculated. We then compared the hardening predictions of both models and interpreted the differences in terms of the relative contributions of geometric (texture) hardening and back-stress hardening, these are also discussed in context of the texture changes predicted. The work hardening values were then interpreted in terms of uniform elongation predictions and its impact on ductility during warm forming.

\section{Materials and Simulations}

In order to study the effect of back-stresses and geometrical hardening in HCP materials, we chose three different polycrystalline metals: $\mathrm{Ti}, \mathrm{Zr}$, and $\mathrm{Mg}$. $\mathrm{Ti}$ and $\mathrm{Zr}$ are very similar systems which produce very similar textures after rolling [7], a consequence of the dominance of prismatic slip. However, zirconium has slightly lower elastic anisotropy and a slightly higher plastic anisotropy than $\mathrm{Ti}$ as can be seen in Tables 1 and 2, that collect the elastic and compliance values and $c / a$ ratios (Table 1) and initial values for the critical resolved shear stresses (CRSS) for each slip family (Table 2) of the three different materials. In Mg, deformation is dominated by basal slip, which is significantly easier than either prismatic or pyramidal slip. Although twinning is also active in all these systems, we have not considered it in our simulations since we are primarily interested in the warm forming behaviour where the amount of twinning is usually limited. Furthermore the texture and loading direction chosen of these materials are such that the amount of twinning expected to occur is small, even at room temperature.

For example, in the case of CP-Ti, the recent works by Bishoyi et al. [8,9] showed that under uniaxial tension and compression experiments volume fraction of twins was reduced when increasing the temperature, being this insignificant at $873 \mathrm{~K}$. Moreover, in [6] we showed that, under 


\section{ACCEPTED MANUSCRIPT}

uniaxial tension, the twined material volume fraction decreased from $2.5 \%$ at RT down to $1 \%$ at 573K. For Zircaloy-2, Xu et al. [10] argued that in their RT elasto-plastic self-consistent model twinning was not included given its low Schmid factor, reproducing experimental RT uniaxial compression results from the same team [11]. Long et al. [12] performed uniaxial compression tests on Zircaloy-2 samples at different temperatures, showing that no twinning was observed at 773K. Finally, for the AZ31 magnesium alloy, Li et al. [13] showed no presence of twinning during warm $(573 \mathrm{~K})$ uniaxial tensile test along the rolling direction (same deformation direction than in the present study). Previously to that, M.R. Barnett [14] showed that twinning "switched off" during uniaxial compression of an AZ31 extruded bar at $\sim 573 \mathrm{~K}$.

Table 1: Elastic [15], compliance [16] and c/a values.

\begin{tabular}{ccccccc}
\hline \hline & $c_{11}(\mathrm{GPa})$ & $c_{33}(\mathrm{GPa})$ & $c_{44}(\mathrm{GPa})$ & $c_{12}(\mathrm{GPa})$ & $c_{13}(\mathrm{GPa})$ & $\mathrm{c} / \mathrm{a}$ \\
\hline CP-Ti & 162.4 & 180.7 & 46.7 & 92.0 & 69.0 & 1.588 \\
Zircaloy-2 & 143.4 & 164.8 & 32.0 & 72.8 & 65.3 & 1.590 \\
AZ31 & 59.7 & 61.7 & 16.4 & 26.2 & 21.7 & 1.624 \\
\hline & $s_{11}\left(\mathrm{GPa}^{-1}\right)$ & $s_{33}\left(\mathrm{GPa}^{-1}\right)$ & $s_{44}\left(\mathrm{GPa}^{-1}\right)$ & $s_{66}\left(\mathrm{GPa}^{-1}\right)$ & $s_{12}\left(\mathrm{GPa}^{-1}\right)$ & $s_{13}\left(\mathrm{GPa}^{-1}\right)$ \\
& $\times 10^{-3}$ & $\times 10^{-3}$ & $\times 10^{-3}$ & $\times 10^{-3}$ & $\times 10^{-3}$ & $\times 10^{-3}$ \\
\hline CP-Ti & 9.6 & 6.8 & 21.5 & 28.6 & -4.7 & -1.8 \\
Zircaloy-2 & 10.2 & 8.0 & 29.9 & 28.6 & -4.1 & -2.5 \\
AZ31 & 22.0 & 19.7 & 61.0 & 59.5 & -7.8 & -5.0 \\
\hline \hline
\end{tabular}

Table 2: Initial CRSS values $(\mathrm{MPa})$

\begin{tabular}{cccc}
\hline & $\pi_{1}^{<c+a>}$ & $P^{<a>}$ & $B^{<a>}$ \\
\hline CP-Ti $[17]$ & 241.2 & 120.0 & 182.4 \\
Zircaloy-2 [10] & 320.0 & 100.0 & 160.0 \\
AZ31 [18] & 110.0 & 88.0 & 20.0 \\
\hline \hline
\end{tabular}

The relative slip activity was varied to simulate the representative changes observed in these materials as the temperature increases. Although there is some data in the literature on the relative slip activity of these materials, these values vary considerably. Therefore we have used a representative value at room temperature and varied the relative slip resistance according to the following. Firstly, from condition RT to R3 in Table 3, we assumed that the thermal contribution to slip resistance is an additional term and that it varies equally for all the slip families under the conditions, except for $\mathrm{Mg}$ where this was only true for $<\mathrm{c}+\mathrm{a}>$ and prismatic slip. For $\mathrm{Mg}$ the CRSS value for the basal slip family is kept constant between RT and R3, this agrees with 


\section{ACCEPTED MANUSCRIPT}

previous studies, where it was shown that CRSS value for basal slip family is insensitive to the increase of temperature $[19,20]$. Secondly, condition R4 for all three materials was design to maximize anisotropy between prismatic and pyramidal slip families in $\mathrm{Ti}$ and $\mathrm{Zr}$ and between basal and pyramidal in Mg. In other words, R4 would represent the situation in which hardening coming from CRSS anisotropy would be more intense. Figure 2 shows the evolution of the CRSS values with the different conditions for each of the materials. Here, we believe it is necessary to stress the fact that, even if between RT and R3 variation of the CRSS values is linear (except for the basal slip system in $\mathrm{Mg}$ ), we do not claim that variation of CRSS with temperature is linear. RT - R4 represent different plastic anisotropies, where the CRSS values at RT come from literature. $\mathrm{R} 1-\mathrm{R} 4$ conditions imply an increase in plastic anisotropy through which the role of geometrical hardening and back-stresses on the overall hardening of three different material systems has been studied.

Table 3: Ratios for the CRSS values considered in each simulation representing an evolution in anisotropy.

\begin{tabular}{ccccccc}
\hline \hline & \multicolumn{2}{c}{$\mathrm{Ti}$} & \multicolumn{2}{c}{$\mathrm{Zr}$} & \multicolumn{2}{c}{$\mathrm{Mg}$} \\
\hline & $\tau^{\pi_{1}^{<c+a>}} / \tau^{P^{<a>}}$ & $\tau^{B^{<a>}} / \tau^{P^{<a>}}$ & $\tau^{\pi_{1}^{<c+a>}} / \tau^{P^{<a>}}$ & $\tau^{B^{<a>}} / \tau^{P^{<a>}}$ & $\tau^{\pi_{1}^{<c+a>}} / \tau^{B^{<a>}}$ & $\tau^{P^{<a>}} / \tau^{B^{<a>}}$ \\
\hline RT & 2.0 & 1.5 & 3.2 & 1.6 & 5.5 & 4.4 \\
R1 & 2.3 & 1.7 & 3.2 & 1.7 & 4.5 & 3.4 \\
R2 & 3.0 & 2.0 & 6.5 & 2.5 & 3.5 & 2.4 \\
R3 & 5.0 & 3.0 & 23 & 7.0 & 2.5 & 1.4 \\
R4 & 12.0 & 1.0 & 23.0 & 1.0 & 5.0 & 1.0 \\
\hline \hline
\end{tabular}

Electron-backscattered diffraction (EBSD) maps were used to generate orientation sets representative of the typical textures after rolling of (i) commercially pure titanium (CP-Ti); (ii) a zirconium alloy (Zircaloy-2); (iii) a magnesium alloy (AZ31). Microstructure was characterized with a FEI Sirion equipped with an Oxford Instruments EBSD camera operating at $20 \mathrm{kV}$ and using a step size of $0.25 \mu \mathrm{m}$. Samples were ground to \#4000 grit paper and finished with OP-S $(0.2 \mathrm{~mm})$ suspension. In the particular case of the AZ31 alloy the sample was electropolished after mechanical polishing to ease indexation, using a $30 \%$ vol. $\mathrm{HNO}_{3}-70 \%$ vol. ethanol electrolyte at $12 \mathrm{~V}$ and $-30^{\circ} \mathrm{C}$. EBSD data was analysed using the commercial Channel 5 software (Oxford Instruments) and then plot using MTEX Toolbox. Average grain sizes for the three materials were $15-20 \mu \mathrm{m}$ for CP-Ti, $20 \mu \mathrm{m}$ for Zircaloy-2 and $15 \mu \mathrm{m}$ for AZ31. Figure 3 shows the pole figures of each of these materials. The CP-Ti (Fig. 3(a)) and Zircaloy-2 (Fig. 3(b)) textures consist of a split of basal poles around normal direction (ND) towards transverse direction (TD) 

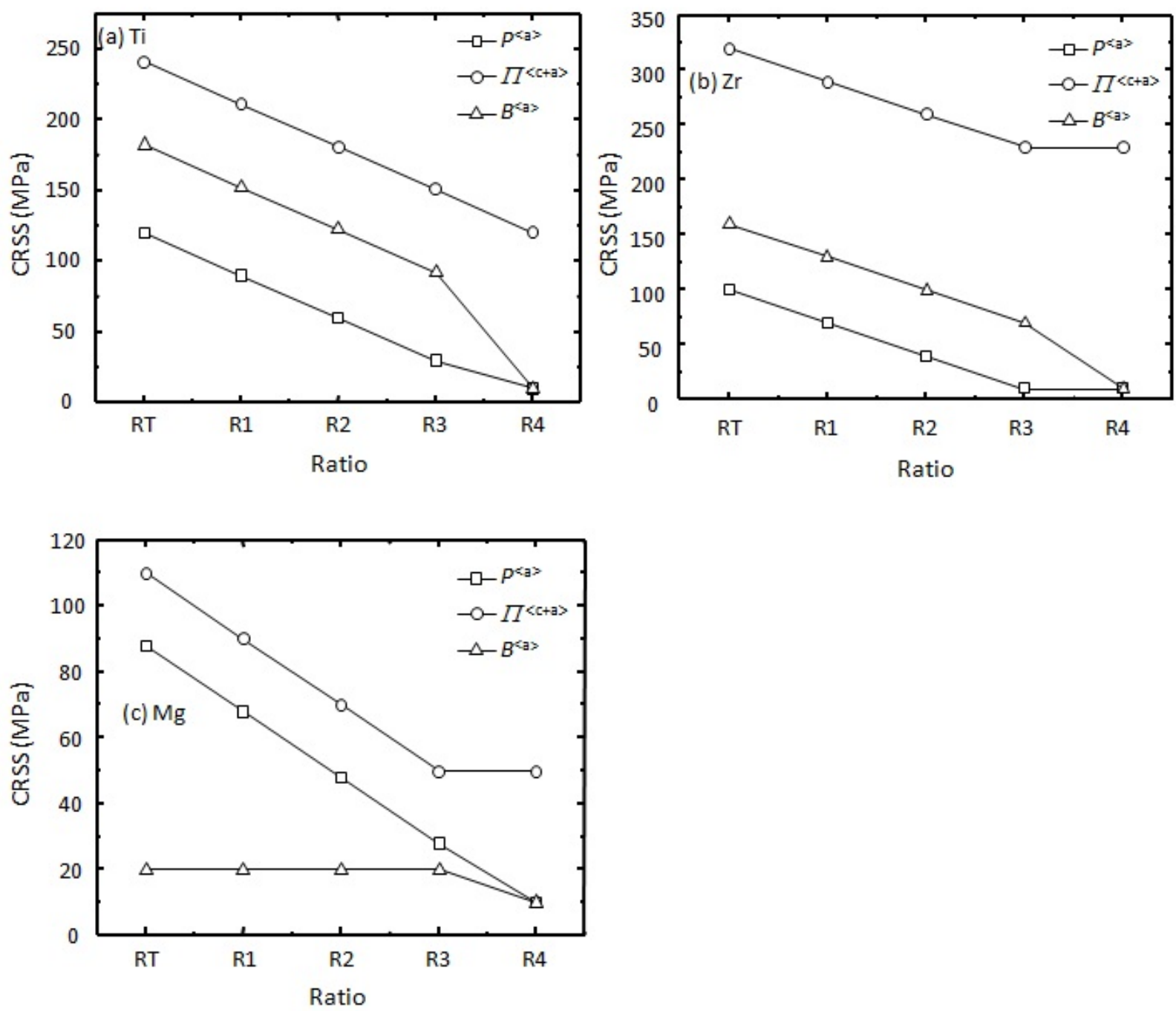

Figure 2: Evolution of CRSS for each slip family and condition in Table 3: (a) Ti, (b) Zr, (c) $\mathrm{Mg}$.

and the spread of $\{11 \overline{2} 0\}$ poles in rolling plane with a maximum in rolling direction (RD). The AZ31 texture (Fig. 3(c)) has a strong basal pole in ND and similar spread of $\{11 \overline{2} 0\}$ poles. The difference in the intensity of the orientation in ND suggests that there are more grains with $<c>$-axis in ND in the AZ31 than those in CP-Ti and Zircaloy-2.

Hereafter we will refer simply to $\mathrm{Ti}, \mathrm{Zr}$ and $\mathrm{Mg}$ systems as the simulations shown here aim to capture the deformation mechanisms in $\mathrm{Ti}, \mathrm{Zr}$ and $\mathrm{Mg}$ when increasing the temperature rather than the precise behavior of CP-Ti, Zircaloy-2 or AZ31 alloys. Moreover, the increase in anisotropy with increasing temperature has been reported for CP-Ti only. Here, we use computational modelling to explore the effects such an effect would have on a Zr-like material, 


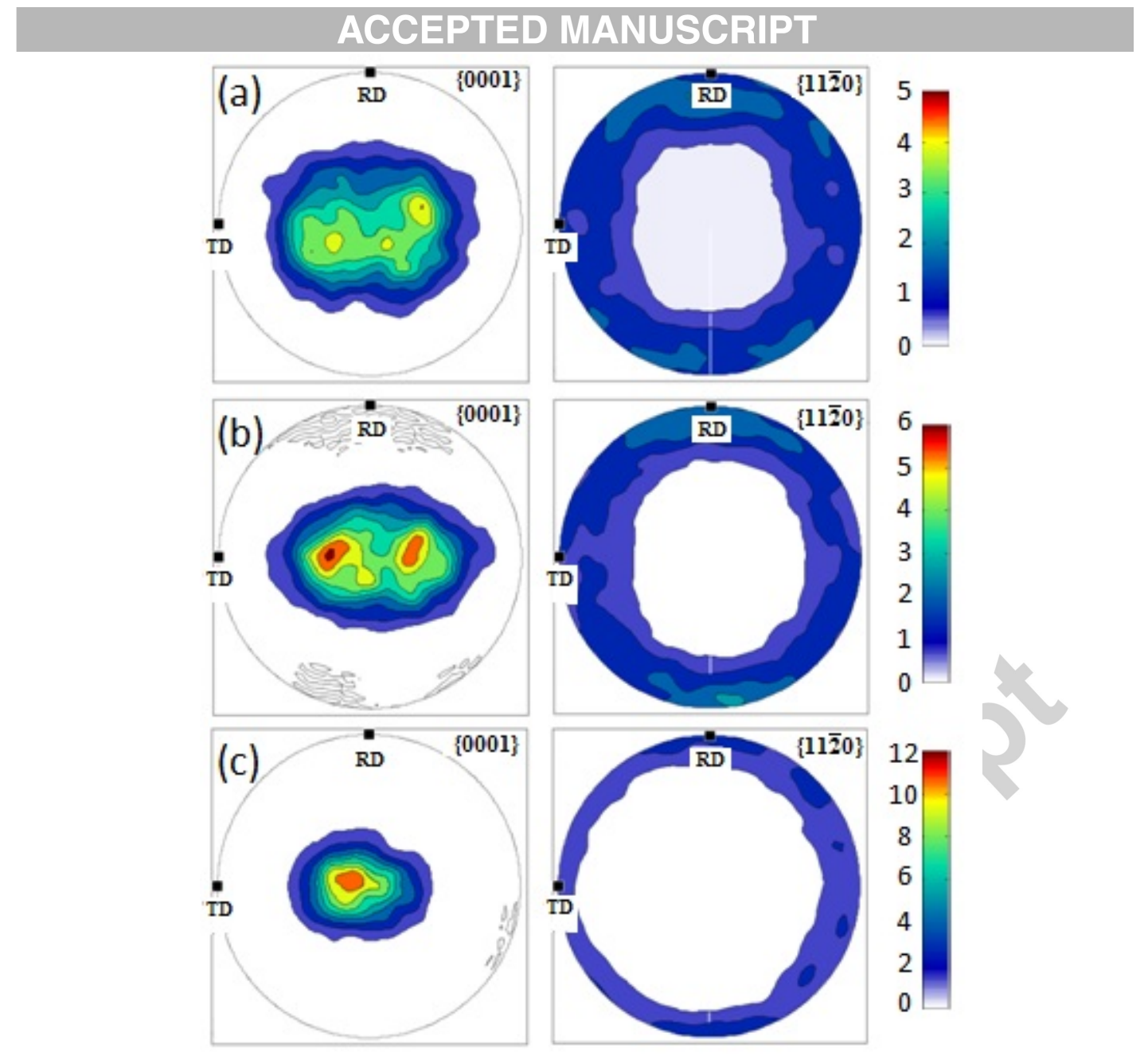

Figure 3: Pole figures representing the initial textures used for both CPFEM and VPSC simulations: (a) CP-Ti, (b) Zircaloy-2, (c) AZ31.

which has different starting texture and a Mg-like material, where basal slip dominates.

For all these three materials we performed CPFEM and VPSC simulations. Initial set of textures for both models was the same (see Fig. 3) and CRSS values were decreased in each simulation, starting from the initial values in Table 2 and reducing them for each new simulation accordingly to the ratios shown in Table 3 and values in Fig. 2. Pole figures in Fig. 3 come from ODFs (orientation density function) represented in the Euler space and projected in the RD TD plane. In order to incorporate this information inside the simulation frameworks, we sampled according to the grain sizes of each of the three materials under study to remove redundant sets of crystallographic orientations. Once this was done, homogeneously distributed sets of orientations were selected depending on the number of elements of each simulation framework (CPFEM or VPSC). 


\section{ACCEPTED MANUSCRIPT}

\subsection{Continuum crystal plasticity finite element modelling}

Three-dimensional crystal plasticity finite element modelling (CPFEM) was used to simulate the uniaxial stress $(\sigma)$ - strain $(\epsilon)$ curves of $\mathrm{Ti}, \mathrm{Mg}$ and $\mathrm{Zr}$. In doing so, first the CRSS values in Table 2 were used along with the corresponding compliance matrix for each material in Table 1. Crystallographic orientations for each material came from experimental EBSD maps, whose pole figures are represented in Fig. 3. The model consisted in a mesh with $15 \times 15 \times 1520$-node isoparametric brick-shaped elements, each containing 8 integration points (IPs). Orientations were given per element hence each of 8 IPs of an element had the same orientation, making a total of 3,375 grains (each element of the CPFEM corresponds to one grain). Boundary conditions were such as the pulling direction in the uniaxial tension simulations was always the rolling direction (RD) in Fig. 3.

Deformation was assumed to occur by slip according to

$$
\frac{\dot{\gamma}^{\alpha}}{\dot{\gamma}_{\mathrm{o}}}=\left(\frac{\tau^{\alpha}}{\tau_{\mathrm{CRSS}}^{\alpha}}\right)^{1 / m},
$$

where $\dot{\gamma}^{\alpha}$ is the increment in shear strain in the $\alpha$ slip system, $\dot{\gamma}_{\mathrm{o}}$ is a nominal reference slip rate, $\tau^{\alpha}$ is the resolved shear stress in the $\alpha$ slip system and $\tau_{\text {CRSS }}^{\alpha}$ is the critical resolved shear stress in each slip system $\alpha$ indicating the level of stress needed to trigger plastic deformation. Here, we did not consider hardening (i.e., increase on the values of $\tau_{\text {CRSS }}^{\alpha}$ ) as we wanted to study the contribution to hardening coming solely from interactions between grains with different orientations. Model was enforced to be rate-insensitive by choosing a low $m$ value equal to 0.02 . The CPFEM implementation used here is explained in detail in [21] for the 2D case.

The mesh size considered in this study $(15 \times 15 \times 15)$ combined with a homogeneous field of IPs rather than grains of defined geometries ensured mesh-insensitive results. Regarding the boundary conditions, the nodes at the planes perpendicular were pinned so only movement along the deformation direction was possible.

\subsection{Visco-plastic self-consistent models}

The viscoplastic self-consistent (VPSC) model is one of the polycrystalline models used to describe the overall properties of an aggregate via the average response of its constituent grains. The VPSC model has been used to successfully predict the plastic anisotropy and texture evolution 


\section{ACCEPTED MANUSCRIPT}

of various materials $[2,3,22]$ and interpret their deformation mechanism [23-25].

In the VPSC model, each grain is considered as an ellipsoidal inclusion separately embedded in a viscoplastic homogenous effective medium (HEM), which has the average properties of all grains of the aggregate. The stress and strain of each grain and then of the HEM are solved in an iterative calculation until the average response of the grains corresponds to the macroscopic stress or strain increments imposed on the aggregate. Interactions between each grain and the HEM are calculated using Eshelby tensors [26]. Each grain is characterized by an orientation and a volume fraction. Plastic deformation in VPSC model is based on slip and twinning. However, in the present paper, only slip mechanisms were used in the simulation for the aforementioned reasons. The hardening of a slip system is expressed via a Voce type hardening law as in Equation 2.

$$
\hat{\tau}^{\alpha}=\tau_{\mathrm{o}}^{\alpha}+\left(\tau_{1}^{\alpha}+\theta_{1}^{\alpha} \Gamma\right) \cdot\left[1-\exp \left(-\Gamma\left|\frac{\theta_{\mathrm{o}}^{\alpha}}{\tau_{1}^{\alpha}}\right|\right)\right]
$$

where $\Gamma=\sum_{\alpha} \Delta \gamma^{\alpha}$ is the accumulated shear in the grain, $\tau_{\mathrm{o}}^{\alpha}$ is the initial critical resolved shear stress (CRSS) which determine the activation of a slip system, $\theta_{0}^{\alpha}$ and $\theta_{1}^{\alpha}$ are the initial and asymptotic hardening rate for the slip system $\alpha$ respectively and $\left(\tau_{\mathrm{o}}^{\alpha}+\tau_{1}^{\alpha}\right)$ is the backextrapolated CRSS.

An individual grain in a VPSC model only interacts to its surrounding HEM. As a result grains with the same orientation should behave in an identical way. However, in a polycrystal, each grain which has the same orientation can behave differently due to the difference in interactions of the grain and its neighboring as discussed earlier on the hardening effects by grain interactions in the Introduction. A more detailed description of the VPSC model can be found elsewhere [2].

A series of uniaxial tensile simulations on $\mathrm{Ti}, \mathrm{Zr}$ and Mg using VPSC were carried out. The hardening parameters in Eq. 2, e.g. $\theta_{\mathrm{o}}^{\alpha}$ and $\theta_{1}^{\alpha}$, are equal to zero, i.e. there is no work hardening in the single crystal constitutive description. Each material was modelled as a HEM consisting of 2000 grains whose initial orientations were obtained from the measured texture given in Figure 3. Each simulation involves 100 strain increments of 0.004 up to a total strain of 0.4 at the strain rate of $0.1 \mathrm{~s}^{-1}$. In addition, relative contribution of each deformation mode to the total shear, i.e. relative activity of slip systems, at each accumulated deformation was computed in the VPSC model.

In this case, boundary conditions were given in the form of deformation gradients. Those 


\section{ACCEPTED MANUSCRIPT}

were imposed to ensure uniaxial deformation along the RD direction. The size of the model ensured that the interaction between each grain and the HEM was independent of the number of grains considered and the deformation gradients imposed were selected to ensure none of the two parameters could affect the results presented here.

\section{Results and discussion}

Figure 4 shows the stress $(\sigma)$ - strain $(\epsilon)$ curves for (a) Ti, (b) Zr and (c) Mg respectively coming from CPFEM and VPSC simulations with the CRSS values in Table 3. Simulations with the VPSC model provide just plastic deformation hence for VPSC the values for deformation in Fig.4 correspond to plastic deformation $\left(\epsilon_{\mathrm{p}}\right)$. In Figure 4, a point in $\epsilon$ is reached above which $\sigma$ decays, marking the initiation of necking. This happens for CPFEM simulations and RT, R1, R2 and R3 conditions but not for the VPSC simulations, that fails in capturing this behavior. As the anisotropy increases going from R1 to R4 the strain at which necking starts increases. In other words, as the anisotropy increases so it does the stage IV work hardening rate, $\mathrm{d} \sigma / \mathrm{d} \epsilon$. This delays the onset of necking, as expected from the Considére's criterion. This can be further seen in Figure 5, where the work hardening rate $\Theta$ is plotted as a function of $\epsilon$ for the three different materials under study and the five CRSS ratios shown in Table 3. Reducing the CRSS values in a way that anisotropy is increased, the resulting stress - strain curves showed an increased work hardening rate and larger ductility. Experimentally, reducing the CRSS values would be analogous to increase the test temperature. During the simulations no external hardening was included, as mentioned in Section 2.1. Any contribution to the overall hardening shown in Figs. 4 and 5 has to come from other sources i.e., back-stresses or geometrical hardening. On the other hand, the simulations for the VPSC model should predict a constant stress, as one would expect from simulations that do not include a hardening definition for any of the slip families. However, when looking at Figs. 4(b) and (c) for the $\mathrm{Zr}$ and $\mathrm{Mg}$ simulations, it is evident that at RT the slope of the $\sigma-\epsilon$ curves is different from zero, indicating a non-zero value for the work hardening rate. These values have not been included in Fig. 5 for representation reasons, but are given in Table 4. As the slope of the $\sigma-\epsilon$ curves for the VPSC simulations is constant, the $\Theta$ value in these cases is well-defined and unique. Looking at Table 4, as the anisotropy increases $\Theta$ tends to decrease, contrary to what happened in the case of the CPFEM simulations. The only possible 

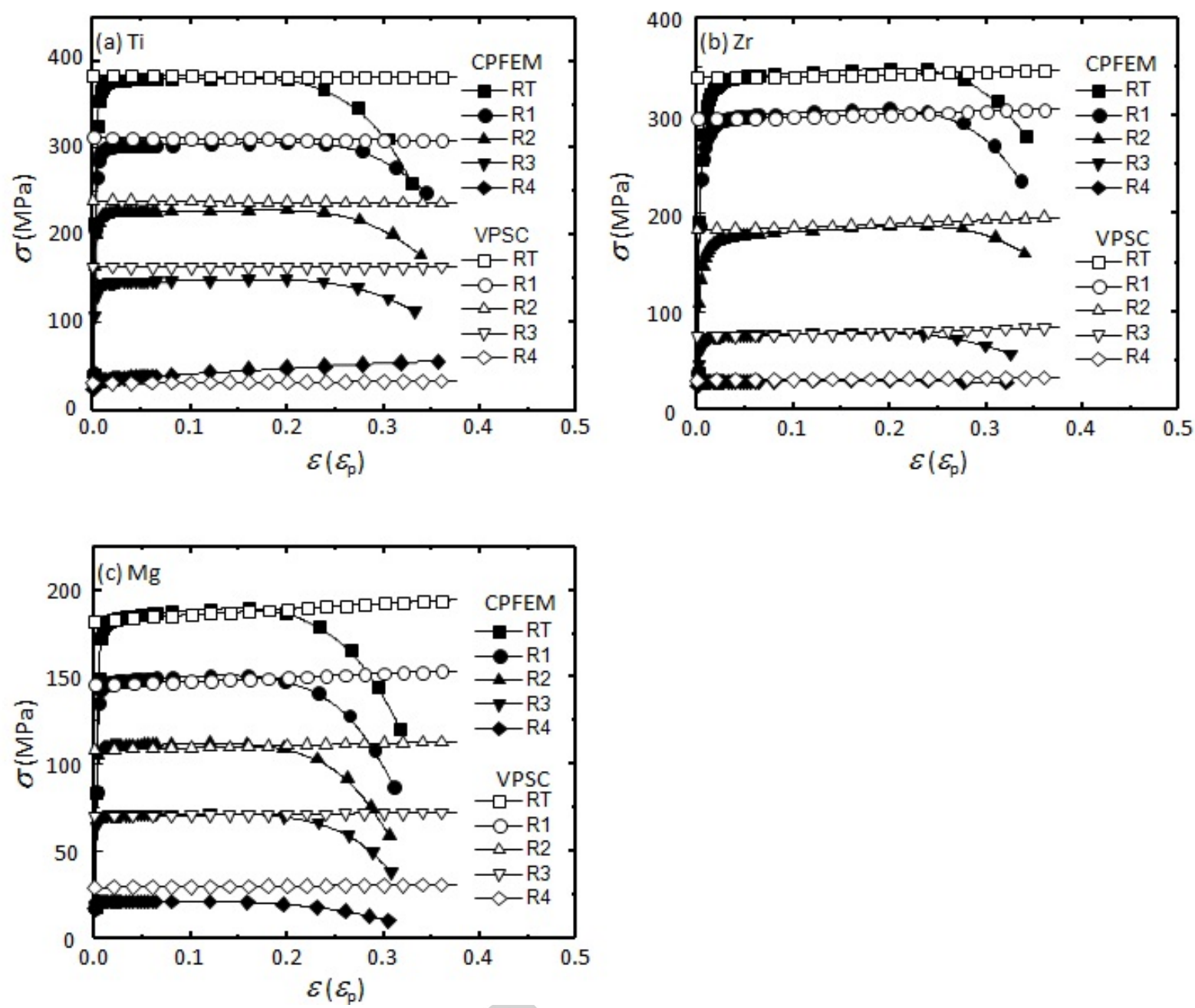

Figure 4: Uniaxial stress $(\sigma)$ - strain $(\epsilon)$ curves for CPFEM (closed symbols) and VPSC (open symbols) simulations with different CRSS ratios (see Table 3 for details): (a) Ti, (b) Zr, (c) Mg. Notice that for VPSC simulations one has to read plastic deformation $\left(\epsilon_{\mathrm{p}}\right)$ in the horizontal axis.

explanation for this is geometric softening caused by texture evolution.

Table 4: Work hardening rate values for the VPSC model for each condition in Table 3. Units in MPa.

\begin{tabular}{cccc}
\hline \hline & $\mathrm{Ti}$ & $\mathrm{Zr}$ & $\mathrm{Mg}$ \\
\hline $\mathrm{RT}$ & -7.0 & 26.8 & 31.7 \\
$\mathrm{R} 1$ & -9.1 & 32.2 & 22.0 \\
$\mathrm{R} 2$ & -7.1 & 39.0 & 13.2 \\
$\mathrm{R} 3$ & 0.0 & 30.4 & 5.9 \\
$\mathrm{R} 4$ & 8.6 & 8.0 & 4.9 \\
\hline \hline
\end{tabular}

Before continuing with the description of the hardening mechanisms in the CPFEM and VPSC 

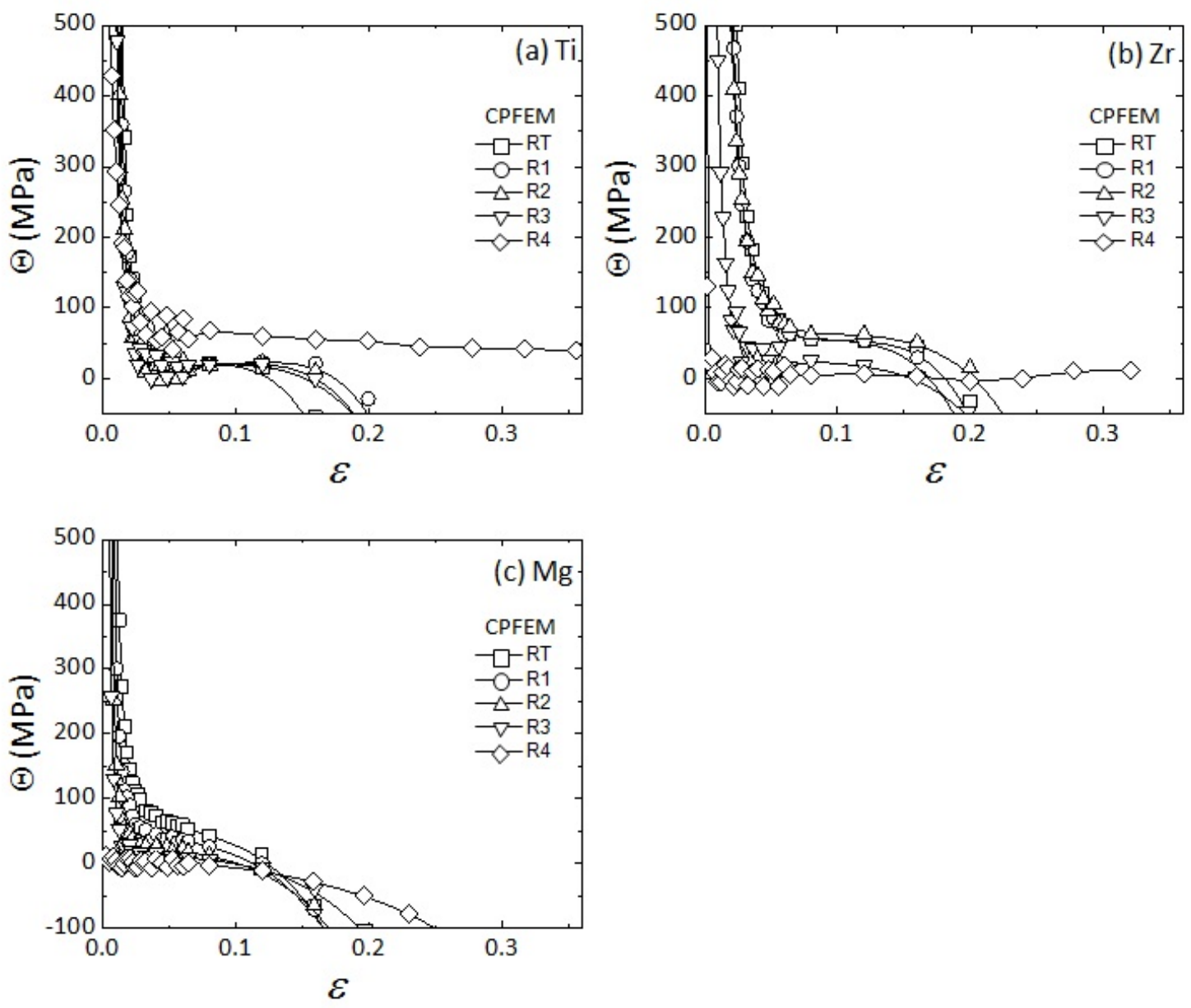

Figure 5: Work hardening rate $(\Theta)$ - strain $(\epsilon)$ curves for the CPFEM simulations at different CRSS ratios (see Table 3 for details): (a) Ti, (b) Zr, (c) Mg.

simulations, it is worthy to discuss more in detail the results in Fig. 5. We will compare the evolution of $\Theta$ with the different anisotropy conditions for Ti, Fig. 5(a), with the ones observed for $\mathrm{Zr}$ and Mg, Figs. 5(b) and (c) respectively. For Ti, it can be observed that R4, the condition introducing the highest anisotropy, produces a $\Theta$ value higher than any of the other conditions. Instead, for Zr, Fig. 5(b), and Mg, Fig. 5(c), $\Theta$ for R4 only surpasses the value for the other anisotropy conditions after a certain deformation, $\epsilon \geq 0.2$ for $\mathrm{Zr}$ and $\epsilon \geq 0.15$ for $\mathrm{Mg}$. These differences in the increase in work hardening rate will be further discussed later in the text in the context of slip activity.

Returning to the description of the hardening mechanisms, for the CPFEM model one has several grains (elements) each of them with a certain orientation according to the textures used in each case (Fig. 3). For example, in the Ti case those grains well aligned for prismatic slip 


\section{ACCEPTED MANUSCRIPT}

will be easier to deform (soft grains) than those aligned with the $\langle c\rangle$ axis paralell to the loading direction (hard grains). As anisotropy increases this effect will be more pronounced, as in comparison it will be much easier to deform the material activating prismatic slip systems than the pyramidal ones. Hence soft grains (those oriented in a way that prismatic slip is possible during deformation) will deform, while hard grains (those oriented in a way that pyramidal slip is the most favorable one) will not. This will contribute to build-up stresses around the hard grains as they will tend to prevent deformation of the soft grains. This will create back-stresses that, ultimately, will contribute to an overall hardening of the material. However, this is not the case for the VPSC mode. Here, each orientation in the considered texture interacts with an average HEM made from the other orientations. Therefore, no neighboring grains/elements interacting with each other and able to create the aforementioned back-stresses. Moreover, as it has been pointed out before, for the VPSC model increasing the anisotropy has the opposite effect of reducing the work hardening rate.

The fact is that the increase in hardening observed with the CPFEM model is an effect of a given texture (soft vs. hard grains creating back-stresses), while the softening experienced by the VPSC simulations is a consequence of texture evolution (geometrical hardening). As explained elsewhere, $[27,28]$, during multiaxial tests on polycrystalline materials, it is not clear how to extract an equivalent $\sigma-\epsilon$ curve from which one could define hardening with an unambiguous scalar value. This is so because the $\sigma-\epsilon$ curve will be highly dependent on the deformation path. In other words, during deformation the texture will evolve as a consequence of crystal rotation and, given that, slip activities will change in a way that stress increases with deformation, producing hardening. The effect of geometrical hardening was seen to be milder with an increase in anisotropy, as can be seen in Fig.4 for the VPSC simulations where increasing anisotropy (RT $\rightarrow \mathrm{R} 4$ ) reduces the slope of the $\sigma-\epsilon$ curve and hence the work hardening rate (Table 4).

Geometric (texture) softening will also be present during CPFEM simulations, rising an apparent paradox, as the work hardening rate increases for CPFEM simulations while it decreases for the VPSC ones. In fact, both mechanisms, back-stresses and geometrical hardening compete during CPFEM simulations. Figures 6 and 7 show the pole figures representing the texture evolution for CPFEM and VPSC simulations respectively. By comparing Figs. 3, 6 and 7 it is evident that VPSC simulations predicted stronger textures than the CPFEM simulations. Selfconsistent models tend to artificially predict stronger textures than full field models since they 

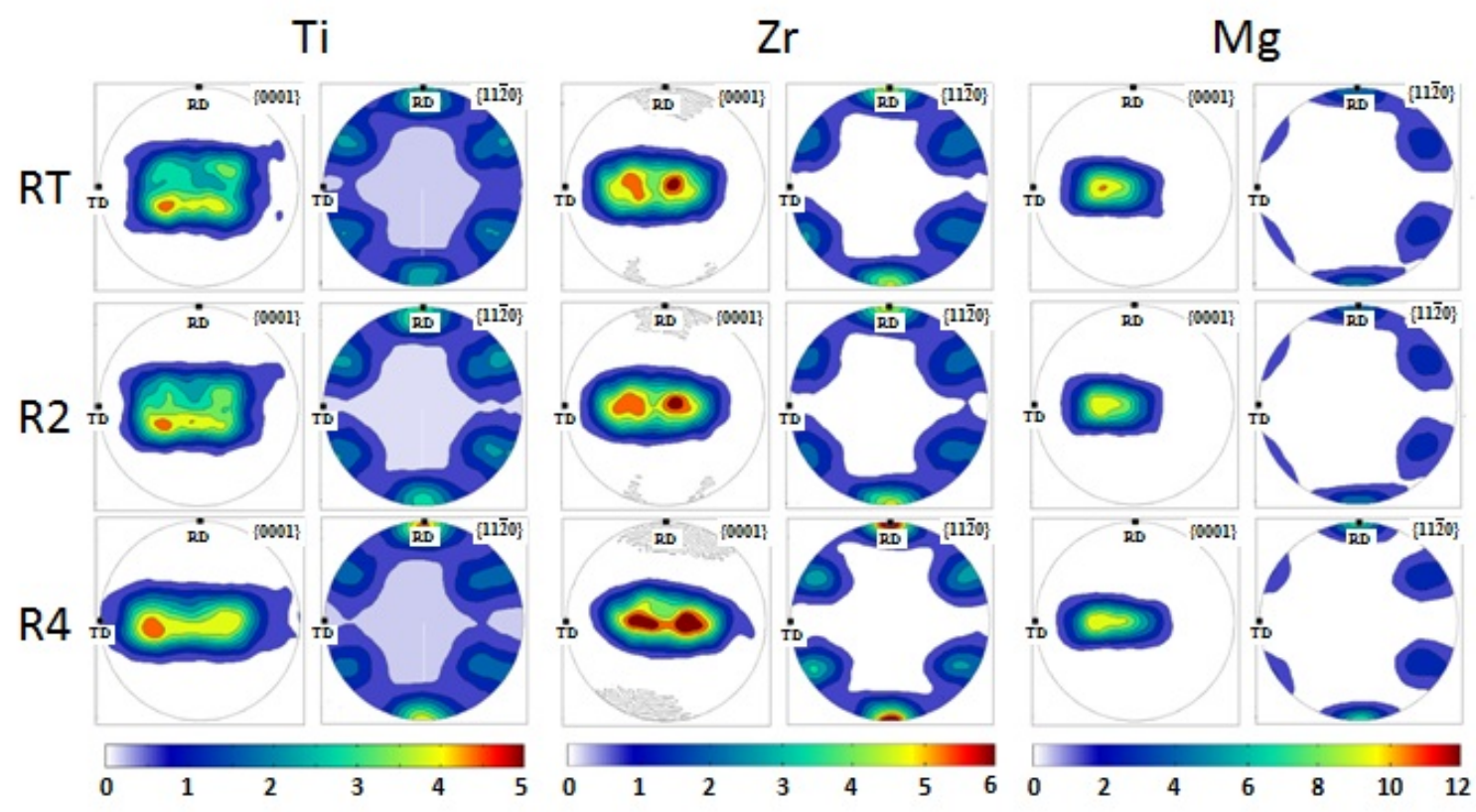

Figure 6: Pole figures representing the evolution of texture during CPFEM simulations at selected CRSS ratios (see Table 3 for details) for $\mathrm{Ti}, \mathrm{Zr}$ and $\mathrm{Mg}$.
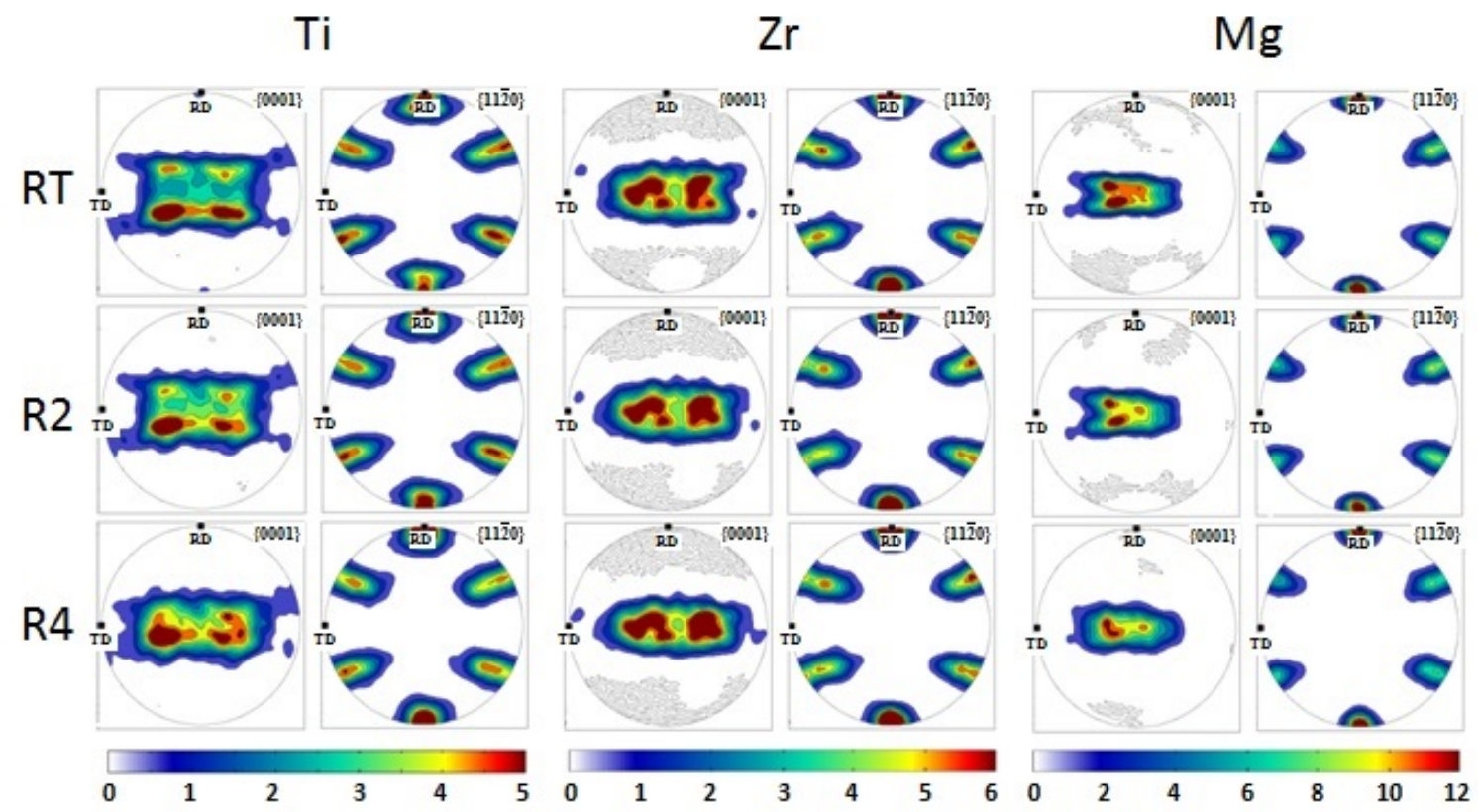

Figure 7: Pole figures representing the evolution of texture during VPSC simulations at selected CRSS ratios (see Table 3 for details) for $\mathrm{Ti}, \mathrm{Zr}$ and $\mathrm{Mg}$.

cannot account for the randomising effects of the interaction between grains. Hence the texture intensity for the CPFEM simulations is weaker when compared to the VPSC simulations. This 

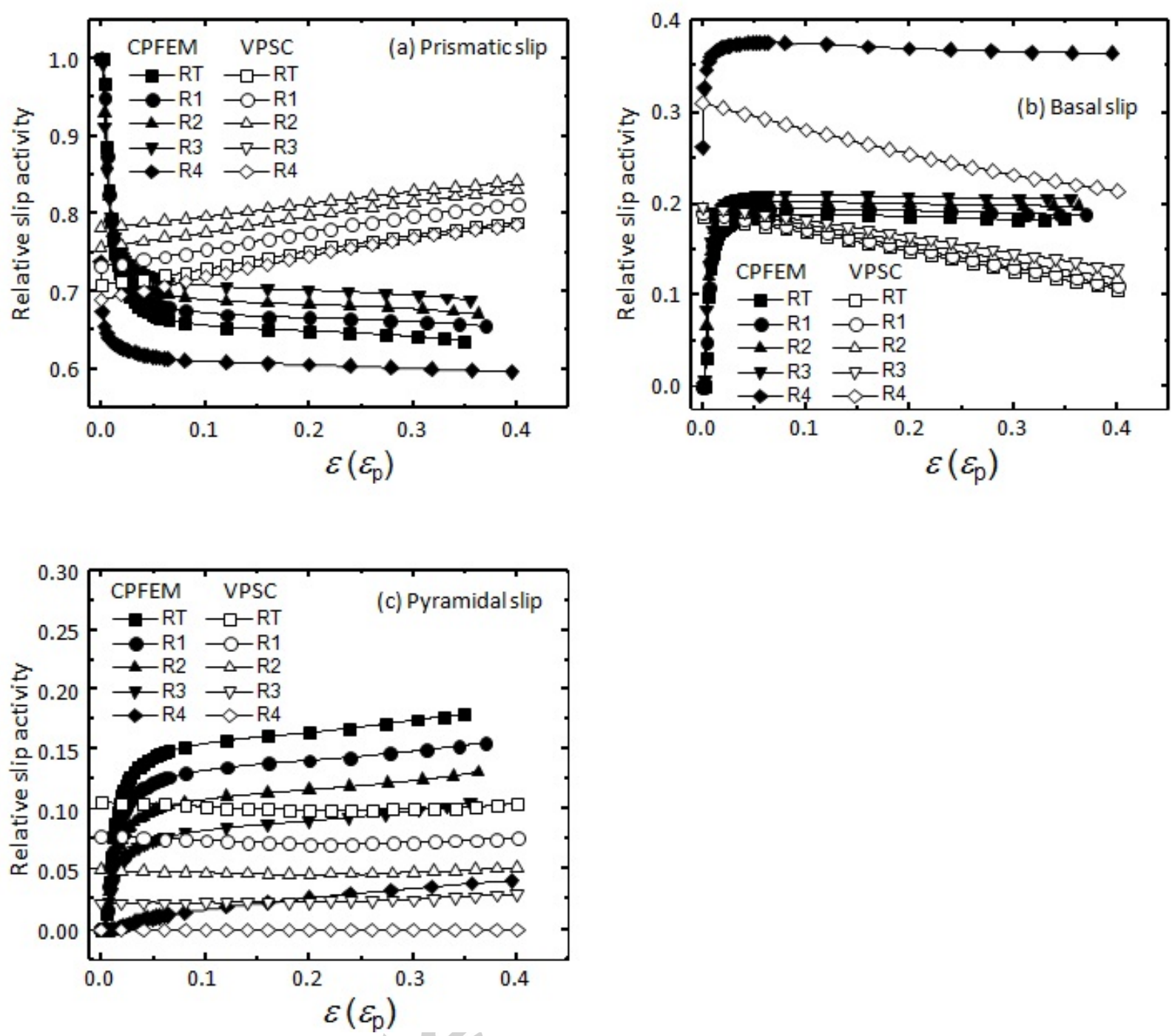

Figure 8: Relative slip activity - deformation $(\epsilon)$ curves for CPFEM (closed symbols) and VPSC (open symbols) simulations on Ti with different CRSS ratios (see Table 3 for details): (a) Prismatic slip, (b) Basal slip, (c) Pyramidal slip. Notice that for VPSC simulations one has to read plastic deformation $\left(\epsilon_{\mathrm{p}}\right)$ in the horizontal axis.

probably also contributes to the domination of back-stress hardening over the softening produced by texture evolution when the anisotropy is increased. This can be further observed in Figure 8, showing the slip activity for each slip family and condition for the Ti CPFEM simulations. One can observe how the increase in anisotropy, going from RT to R4, reduces the slip activity in the pyramidal $<\mathrm{c}+\mathrm{a}>$ slip family (Fig. $8(\mathrm{c})$ ), while the activity in the prismatic slip family (Fig. 8(a)) increases. However, there is an exception to this when considering R4. In this case there is a transfer in slip activity from prismatic to basal slip (Fig. 8(b)), while pyramidal slip continues to reduce, when considering both CPFEM and VPSC simulations. This can be easily 

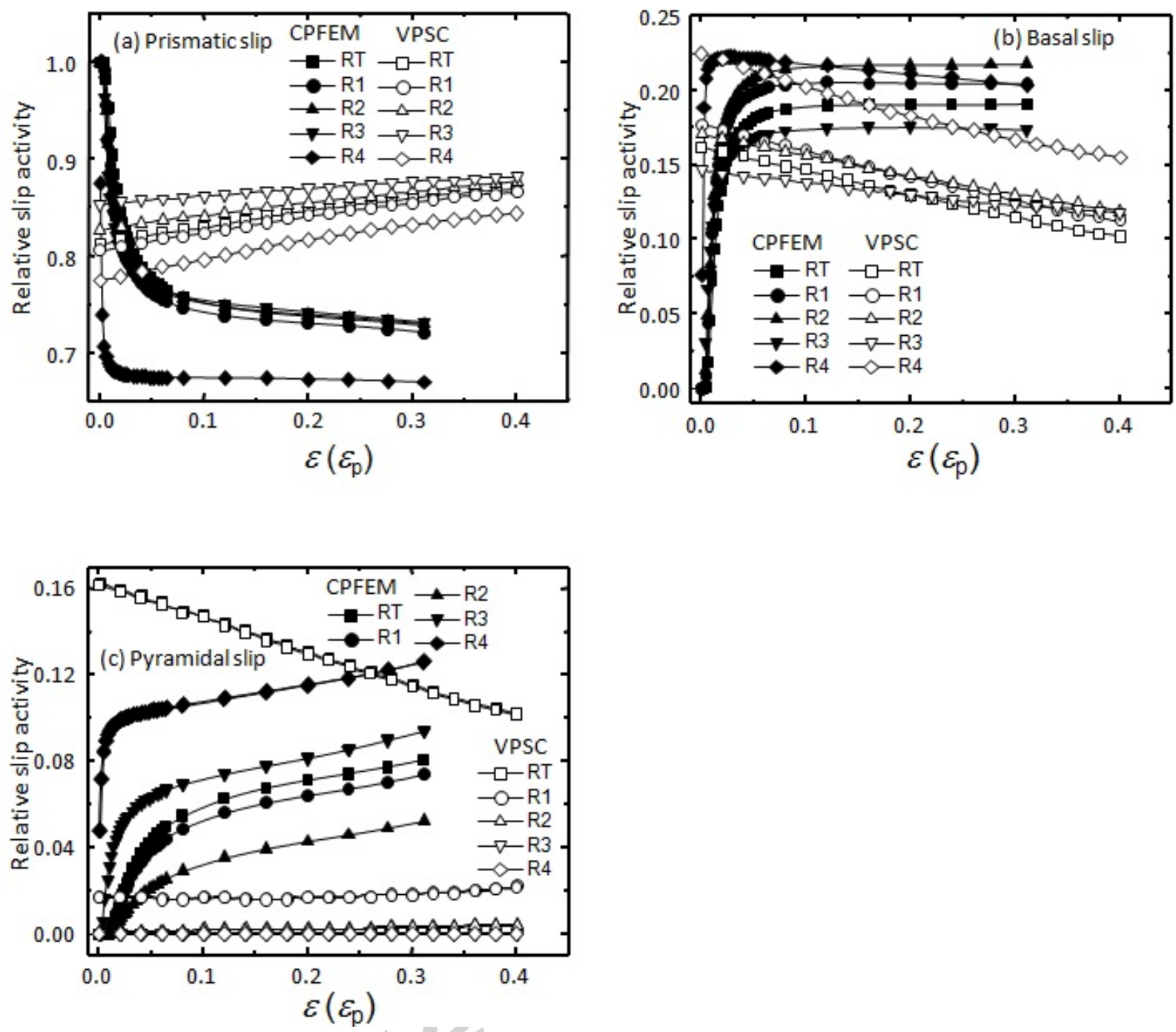

Figure 9: Relative slip activity - deformation $(\epsilon)$ curves for CPFEM (closed symbols) and VPSC (open symbols) simulations on $\mathrm{Zr}$ with different CRSS ratios (see Table 3 for details): (a) Prismatic slip, (b) Basal slip, (c) Pyramidal slip. Notice that for VPSC simulations one has to read plastic deformation $\left(\epsilon_{\mathrm{p}}\right)$ in the horizontal axis.

understood if one realizes that for R4 the imposed CRSS values for prismatic and basal slip are identical (see Figure 2 and Table 3) and the particular initial texture can make basal slip more favorable that prismatic slip. Indeed, when observing Figs. 6 and 7 for R4 one realizes that the texture is elongated in the TD direction, that is precisely what one would observe experimentally in Ti when performing uniaxial tests at high temperature (having high anisotropy in the CRSS ratios as in R4). Along these lines, it is interesting to observe the slip activities for $\mathrm{Zr}$ and $\mathrm{Mg}$ in Figures 9 and 10, respectively, for the CPFEM simulations. In the case of $\mathrm{Zr}$, one can see that for condition R4 prismatic slip decreases (Fig. 9(a)) as it was doing for Ti but, more importantly, 

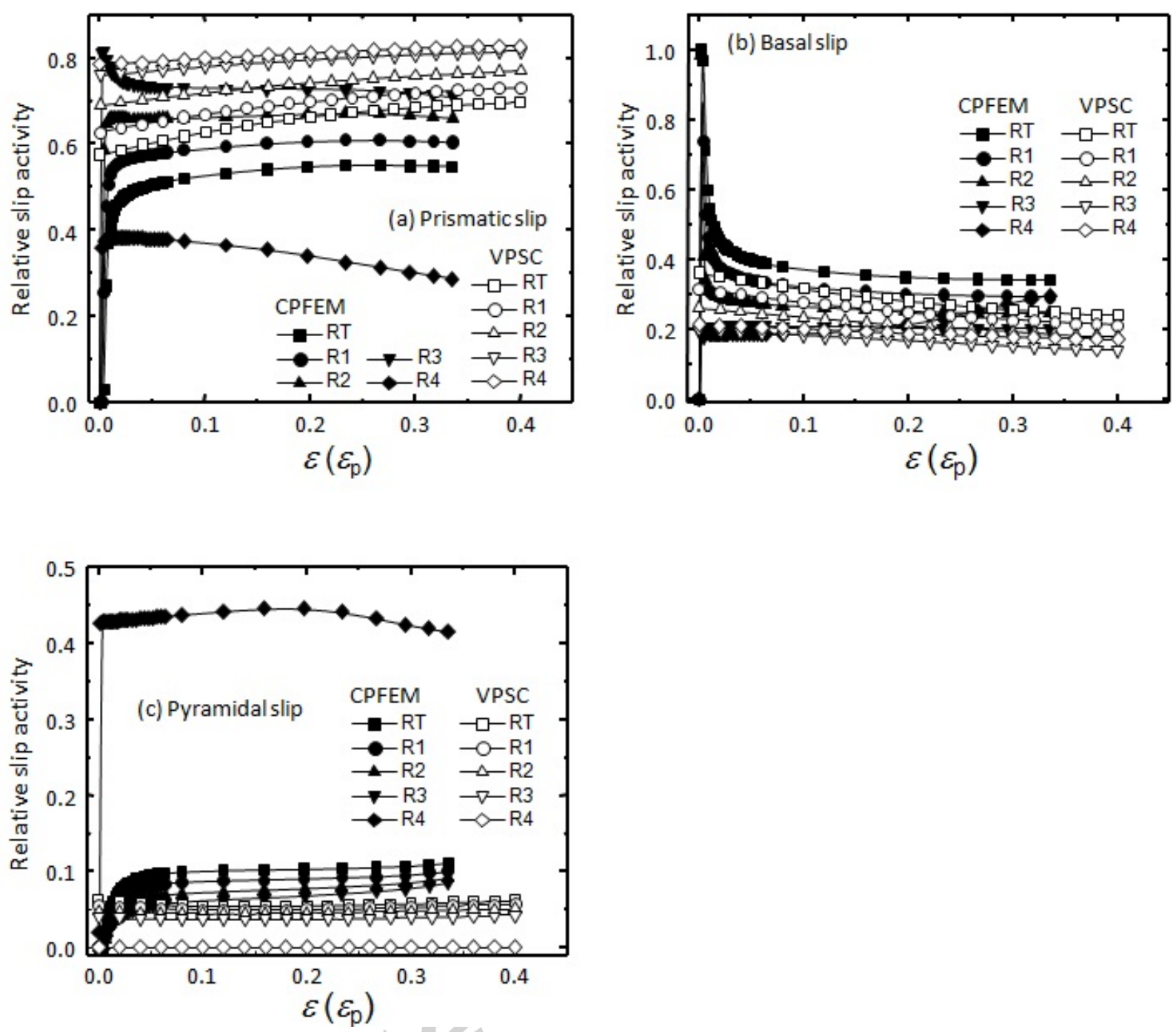

Figure 10: Relative slip activity - deformation $(\epsilon)$ curves for CPFEM (closed symbols) and VPSC (open symbols) simulations on Mg with different CRSS ratios (see Table 3 for details): (a) Prismatic slip, (b) Basal slip, (c) Pyramidal slip. Notice that for VPSC simulations one has to read plastic deformation $\left(\epsilon_{\mathrm{p}}\right)$ in the horizontal axis.

pyramidal slip (Fig. 9(c)) increases, opposite to what happened for Ti. Hence in this case we have that prismatic slip activity is reduced in favour of pyramidal slip activity, even if for small $\epsilon$ basal slip activity increases (Fig. 9(c)). The same occurs for the slip activity in Fig. 10 for Mg and condition R4. Here, the reduction in prismatic slip activity (Fig. 10(a)) in favour of pyramidal slip activity (Fig. 10(c)) is even more important than for $\mathrm{Zr}$ (for $\mathrm{Mg}$, basal slip activity continuously decreases when going from RT to R4). This decrease in prismatic slip activity and increase in pyramidal slip activity is the reason why the increase in work hardening rate in Fig. 5 is milder for $\mathrm{Zr}$ and $\mathrm{Mg}$ compared to $\mathrm{Ti}$. Actually, for $\mathrm{Zr}$ and $\mathrm{Mg}$, the role of hard grains is 


\section{ACCEPTED MANUSCRIPT}

played by the basal grains, as is the basal slip activity the one that is reduced when increasing the CRSS anisotropy.

Lets now go back to the texture evolutions shown in Figs. 6 and 7 for CPFEM and VPSC simulations, respectively. For $\mathrm{Mg}$ a strong basal texture in the RD-TD plane is observed, indicating that the majority of the hexagonal prisms had their c-axis perpendicularly oriented respect to $\mathrm{RD}$ and the basal planes laid parallel to the RD-TD plane. As the material is deformed along $\mathrm{RD}$, the basal planes rotate to lay parallel to the tensile axis, indicating basal slip dominates the deformation. Looking at the prismatic planes, one can see the maximum intensity distributed along the stereographic circle and separated $60^{\circ}$ from each other (See the work by Khan et al. [29] for a complete study on texture evolution of AZ31 alloy under tension at different temperatures). In the case of $\mathrm{Ti}$ and $\mathrm{Zr}$ alloys, prismatic slip is the easiest slip mode and it makes possible a spread of the split basal poles along TD, as it can be seen in Figs. 6 and 7. The spread of the $\{11 \overline{2} 0\}$ poles in rolling plane becomes more evident, specially for the two maximums along RD.

Finally, it is worth mentioning the fact that, even if the CPFEM and VPSC models used to simulate the behavior of $\mathrm{Mg}$ do not include twinning, the results show that to fully simulate hardening in these materials one should take into account back-stresses and geometrical hardening besides twin hardening. Knezevic at al. [30] show"strong evidence against the currently accepted notion in $\mathrm{Mg}$ deformation literature that the unusually high strain-hardening rates in AZ31 are due, directly, to texture hardening caused by activation of extension twins". As aforementioned, increasing the CRSS anisotropy for the different slip families is equivalent to increase the test temperature and, at higher temperatures twinning will be less important or even inactive (see for example the work by Li et al [13]).

\section{Conclusions}

CPFEM and VPSC simulations of uniaxial tensile tests were performed in three hcp materials: $\mathrm{Ti}, \mathrm{Zr}$ and $\mathrm{Mg}$. Using representative textures, obtained experimentally, as the starting textures, the simulations did not include any slip hardening or twinning. Hence any contribution to the overall work hardening rate must came from either back-stresses or geometrical hardening. The results show that in the CPFEM simulations the materials exhibited work hardening, which increased with increasing slip anisotropy. The VPSC simulations, on the other hand, decrease 


\section{ACCEPTED MANUSCRIPT}

in the work hardening rate with the increase in anisotropy. This difference is a consequence of the effect of back-stresses which cannot be accounted for in the VPSC simulations. The softening observed in the VPSC simulations is a consequence of the change in texture with uniaxial straining. In fact, both mechanisms are present in the CPFEM simulations, but backstresses have a bigger influence. Hence we demonstrate that back-stresses ought to be taken into account when describing the work hardening in HCP materials, especially during warm forming when other contributions to work hardening like twinning are limited if not inexistent. It has been shown that the CPFEM simulation framework is the preferred simulations framework in order to account for both, geometrical hardening and back-stresses.

Acknowledgments- The authors would like to thank the EPSRC for funding this study through the programme grant EP/H020047/1, Light Alloys for Sustainable Transport 2nd Generation (LATEST2) and programme grant EP/R001715/1, LightForm.

Data availability- The raw data required to reproduce these findings are available to download from http://dx.doi.org/10.17632/5xmgk782tb.2. The processed data required to reproduce these findings are available to download from http://dx.doi.org/10.17632/5xmgk782tb.2.

\section{References}

[1] W. Wen, M. Borodachenkova, C.N. Tomé, G. Vincze, E.F. Rauch, F. Barlat, J.J. Grácio, Int. J. Plast. 73 (2015) 171-183.

[2] R.A. Lebensohn, C.N. Tomé, Acta Metall. Mater. 41 (1993) 2611-2624.

[3] R.A. Lebensohn, C.N. Tomé, Mater. Sci. Eng. A 175 (1994) 71-82.

[4] K. Tanaka, T. Mori, Acta Met. 18 (1970) 931-941.

[5] K.V. Mani Krishna, D.G. Leo Prakash, G. Timár, A. Fitzner, D. Srivastava, N. Saibaba, J. Quinta da Fonseca, G.K. Dey, M. Preuss, Mater. Sci. Eng. A 650 (2016) 497-509.

[6] A. Orozco-Caballero, F. Li, D. Esqué-de los Ojos, M. Atkinson, J. Quinta da Fonseca, Acta Mater. 149 (2018) 1-10. 


\section{ACCEPTED MANUSCRIPT}

[7] M.J. Philippe, M. Serghat, P. Van Houtte, C. Esling, Acta Metall. Mater. 43 (1994) $1619-1630$.

[8] B.D. Bishoyi, R.K. Sabat, J. Sahu, S.K. Sahoo, Mater. Sci. Eng. A 703 (2017) 399-412.

[9] B.D. Bishoyi, R.K. Sabat, S.K. Sahoo, Mater. Sci. Eng. A 718 (2018) 398-411.

[10] F. Xu, R.A. Holt, M.R. Daymond. Journal of Nuclear Materials, 373 (2008) 217-225.

[11] F. Xu, R.A. Holt, M.R. Daymond, R.B. Rogge, E.C. Oliver, Mater. Sci. Eng. A 488 (2008) 172-185.

[12] F. Long, F. Xu, M.R. Daymond, Metall. Mater. Trans A 44 (2013) 4183-4193.

[13] N. Li, G. Huang, X. Zhong, Q. Liu, Mater. Des. 50 (2013) 382-391.

[14] M.R. Barnett, Metall. Mater. Trans. A 34 (2003) 1799-1806.

[15] X.L.B. Freund, S. Suresh, Thin Films, Cambridge University Press, Cambridge, 2003.

[16] Y.D. Tromans, Int. J. Rev. Appl. Sci. 6 (2011) 462-483.

[17] B. Barkia, V. Doquet, J.P. Couzinié, I. Guillot, E. Héripré. Mater. Sci. Eng. A 636 (2015) 91-102.

[18] A. Chapuis, Z.-q. Wang, Q. Liu, Mater. Sci. Eng. A 655 (2016) 244-255.

[19] A. Chapuis, J.H. Driver, Acta Mater. 59 (2011) 1986-1994.

[20] C.J. Boehlert, Z. Chen, I. Gutiérrez-Urrutia, J. Llorca, M.T. Pérez-Prado, Acta Mater. 60 (2012) 1889-1904.

[21] P. Bate, Phil. Trans. R. Soc. Lond.357 (1999) 1589-1601. 


\section{ACCEPTED MANUSCRIPT}

[22] C.N. Tomé, P.J. Maudlin, R.A. Lebensohn, G.C. Kaschner, Acta Mater. 49 (2001) 30853096.

[23] S.-B. Yi, C.H.J. Davies, H.-G. Brokmeier, R.E. Bolmaro, K.U. Kainer, J. Homeyer, Acta Mater. 54 (2006) 549-562.

[24] J.P. Escobedo, E.K. Cerreta, C.P. Trujillo, D.T. Martinez, R. a. Lebensohn, V. a. Webster, Acta Mater. 60 (2012) 4379-4392.

[25] P.A. Pandey, A.S. Khan, E.Y. Kim, S.H. Choi, T. Gnäupel-Herold, Int. J. Plast. 41 (2013) 165-188.

[26] J.D. Eshelby, Proc. Phys. Soc. London, Ser. A. 241 (1957) 376-396.

[27] R. J. Asaro, A. Needleman, Acta Metall. 33 (1985) 923-953.

[28] M.G. Stout, U.F. Kocks, Texture and Anisotropy (edited U.F Kocks, C.N. Tomé and H.-R. Wenk), p. 458 Cambridge University Press, Cambridge (1998).

[29] A.S. Khan, A. Pandey, T. Gnäupel-Herold, R.K. Mishra, Int. J. Plast. 27 (2011) 688-706.

[30] M. Knezevica, A. Levinsona, R. Harrisa, R.K. Mishrab, R.D. Dohertya, S.R. Kalidindi, Acta Mater. 58 (2010) 6230-6242. 